\title{
GEOMETRIC MODELLING OF TREE ROOTS WITH DIFFERENT LEVELS OF DETAIL
}

\author{
J.I.Guerrero Iñiguez* \\ Centro de Investigación en Geografía y Geomática"Ing. Jorge L. Tamayo", A.C., Contoy 137, Ciudad de México, México - \\ jguerrero@centrogeo.edu.mx
}

KEY WORDS: tree root, geometric modelling, taproot, heart-root, surface-roots, Levels of Detail, CityGML

\section{ABSTRACT:}

This paper presents a geometric approach for modelling tree roots with different Levels of Detail, suitable for analysis of the tree anchoring, potentially occupied underground space, interaction with urban elements and damage produced and taken in the built-in environment. Three types of tree roots are considered to cover several species: tap root, heart shaped root and lateral roots. Shrubs and smaller plants are not considered, however, a similar approach can be considered if the information is available for individual species. The geometrical approach considers the difficulties of modelling the actual roots, which are dynamic and almost opaque to direct observation, proposing generalized versions. For each type of root, different geometric models are considered to capture the overall shape of the root, a simplified block model, and a planar or surface projected version. Lower detail versions are considered as compatibility version for 2D systems while higher detail models are suitable for 3D analysis and visualization. The proposed levels of detail are matched with CityGML Levels of Detail, enabling both analysis and aesthetic views for urban modelling.

\section{INTRODUCTION}

Geometric modelling of trees is important as trees are a fundamental part of cities and interactions between urban objects always occur. The root system architecture is a fundamental part of the tree and its study is relevant for urban planning as the urban underground space is shared with various objects like sewers, water, gas and oil pipes, electrical and heating systems, subways, building foundations, among many objects, and spatial interaction exist between them. Interactions occur and change continuously as tree roots grow and invade contiguous space but also when management of urban objects is performed and roots are pruned.

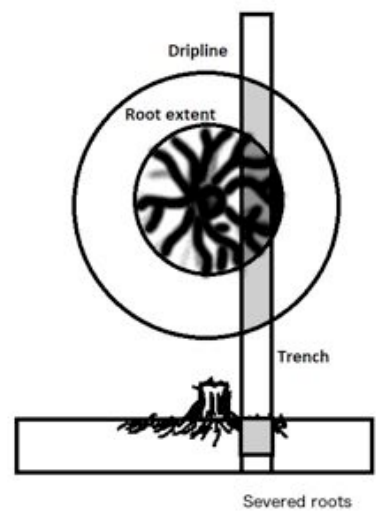

Figure 1. Plan view of a tree showing the outline of the canopy or dripline, the root extents and a trench dug through the root zone severing the roots. This view reflects a geometric interaction between the trench and the tree root where both interiors and borders intersect.

The concept of interaction between objects is borrowed from the PostGIS ST_RELATE function (PostGIS, 2017) where two geometries relate if the evaluation of an intersection matrix returns true. The considered intersection matrix is based on the Dimensional Extended 9 Intersection Model (DE-9IM) (Clementini, et al, 1993) and only intersections between interior and boundaries are considered as direct interactions between objects. Figure 1. shows an example of direct interaction between a tree root and a trench with negative effects on the tree. The effects of trees and tree roots interaction occur not only when sharing the same space within their boundaries but also with neighbouring objects at distances beyond their geometric boundary. Therefore, the distance between vegetation and urban infrastructure is also critical to quantify the mutual effects and damage, support its management and decisionmaking activities, requiring an analytical description derived from geometric models.

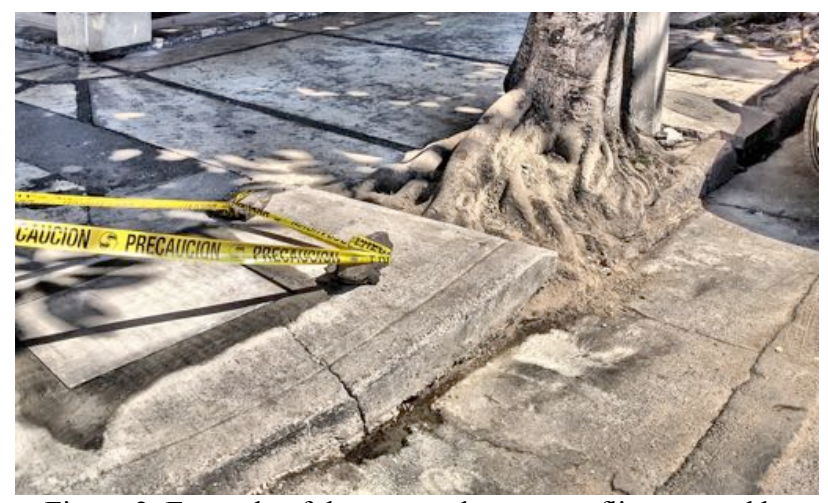

Figure 2. Example of damage and space conflicts caused by proximity of tree roots to urban elements, including pavement cracks, sewer system, electric poles and electrical pit damage. The tree species correspond to Ficus elastica, a common species in Mexico City (CONABIO, 2012).

A simple classification scheme for damage or potential damage is based on the type of physical interaction: direct and indirect (Overbeke, 2010). Direct damage is caused by mechanical action or contact of the stem or branches and occurs when two objects occupy the same space and their integrity is compromised. Roots also produce direct damage by following the least resistance path, however, the continuous radial expansion exerts pressure, displacing structures. In urban environments, trees grow with root restrictions and they produce visible effects by breaking the pavement, sidewalks or curbs. In other cases, roots interfere with underground infrastructure as root systems follow the water gradient. 
Damaged infrastructures include water systems, drainage, electricity, steam, gas, and telecommunications (Calaza et al., 2016). By following the least cost path to the water source, they block, rise or break pipes, telecommunications, water distribution networks or electric networks (Calaza et al., 2016). Figure 2. shows a tree sharing space with the urban infrastructure producing damages.

Indirect damage is caused by the influence of soil moisture levels, modifying the substrate physical properties as seasons change. One example is subsidence damage to low-rise buildings when trees damage the foundation of the buildings. Tree roots extract moisture from the soil and specifically, clay reacts by contracting and expanding allowing building foundations to move downwards, resulting in cracks. A study from Mercer et al (2011) showed ten genera of trees related to subsidence events at distances greater than 10 meters. Calaza et al. (2016) present examples of tree species classified according to the recommended distance to buildings in order to avoid damages with distances ranging from 7 to 20 meters.

Other types of problem occur when tree roots fail. In this case, the damage is not caused by the roots themselves but from the falling tree. Tree roots constitute the anchor of trees so they stand erect, support the gravity loads and withstand the winds (Coder, 2014). The wind resistance is a function of the anchoring or root/soil interaction, wind and gravitational forces applied to the canopy (Stathers et al, 1994). Achim et al. (2009) present a mechanistic resistance model for uprooting based on easily measurable parameters where the root-plate spread is an important factor for anchorage strength and the rooting depth increases the anchorage strength.

Tree failures caused by the wind can be categorized into four types (Stathers et al, 1994): 1) steam break where the bole of the tree breaks above the ground, 2) stock break where bole breaks at ground level, 3) root break via a rotational failure and pivoting on broken roots and 4) tree throw where the tree is uprooted, pivoting on the outer edge of a massive plate of roots and soil.

Tree anchorage factors have been successfully identified including the stem diameter, tree diameter-height relationship and tree weight. Additional elements are considered key to tree anchoring including 1) soil fracture resistance, 2) windward major roots resistance to pull out and breaking tension, 3) tree weight on soil, 4) leeward roots resistance to buckling in compression and snapping 5) splitting resistance from stem base, large roots and a wide stiff support platform (Coder, 2014).

Urban environments can limit the growth of the roots, weakening the anchoring of the trees, producing a low stability and producing dangerous trees (Calaza et al, 2016). In addition, root/soil combination is important for the stability of the tree, as a modified root morphology affects the anchorage.

The risk of failure increases if the most important roots are cut or damaged as the friction between soil and roots decreases (Calaza et al, 2016). The California Tree Report Program Statistics (University Of California, 2017) reports 6034 tree fails. A 2010 summary from the mentioned program (University Of California, 2010) relates $36 \%$ of the tree fails to radicular failures, where four genera accounted for $68 \%$ of the general failure reports, radicular or not. Figure 3 shows an example of tree damage due excessive root pruning.

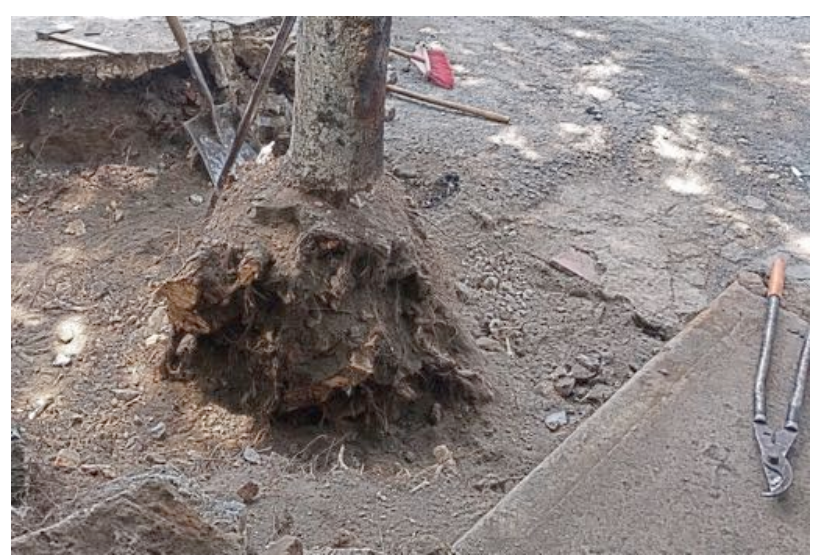

Figure 3. Root mutilated from maintenance works performed from a non-specialized informal contractor. Principal roots were cut and root anchoring lost as the specimen, Liquidambar styraciflua or Sweetgum, develops surface or lateral roots and "severing one major root ... may kill up to 25 percent of the tree root system" (Shamoon, 2012). The tree was removed next day due to severe instability.

In general, major roots, its extension, and depth have a geometrical component, i.e. shape, size, and position. The different depth and lateral extension configurations allow supporting different loads, as they maximize the friction between roots and soil, which is the main force that keeps the tree erect and prevents roots from pulling out (Coder, 2010).

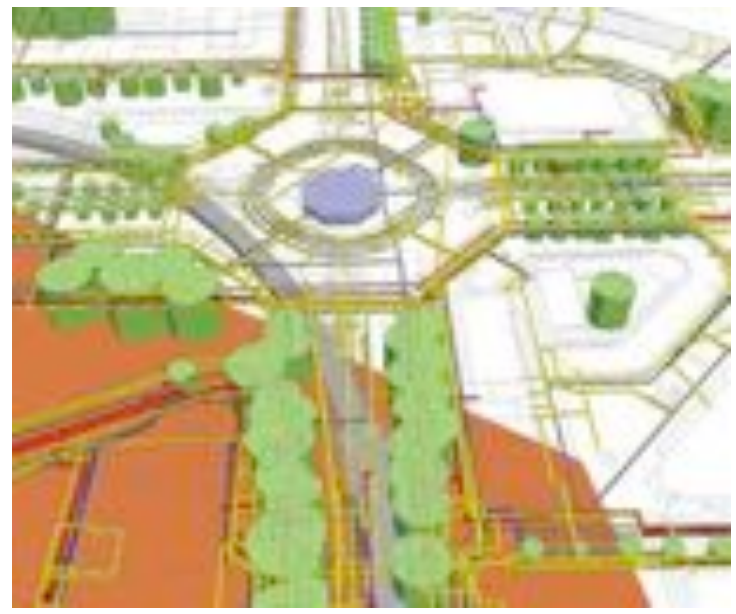

Figure 4. The sewer system of the City of Rotterdam and a set of tree roots modelled as cylinders. The interaction between both datasets is visible as occlusion of urban infrastructure. Image courtesy of the City of Rotterdam.

Damage to urban infrastructures are considered as ecosystem disservices, i.e. a function of ecosystems perceived as negative to human beings (Lyytimäki et al, 2009), having economic, social and cultural costs (Gómez-Baggethun et al, 2013).

So far, the mentioned information reflects how the anchorage and stability of the tree are defined by the shape or geometry of trees, but also how their extension reflects the damage taken and produced due to physical interactions. Geometric representations of tree roots allow to analyze the anchorage system of the root, damage caused to urban infrastructure and received from maintenance works. Figure 4 shows an urban example based on vector data, where space conflicts occur between underground infrastructure and tree roots. The 
simultaneous visualization of pipes occluded by tree roots helps to understand the influence of tree roots over the surrounding elements and how given the importance of the underground elements, repair and maintenance works could harm the root and tree integrity. An example of maintenance works performed on the electrical network is presented in Figure 5, where workers must deal with space conflicts and end up damaging tree roots.

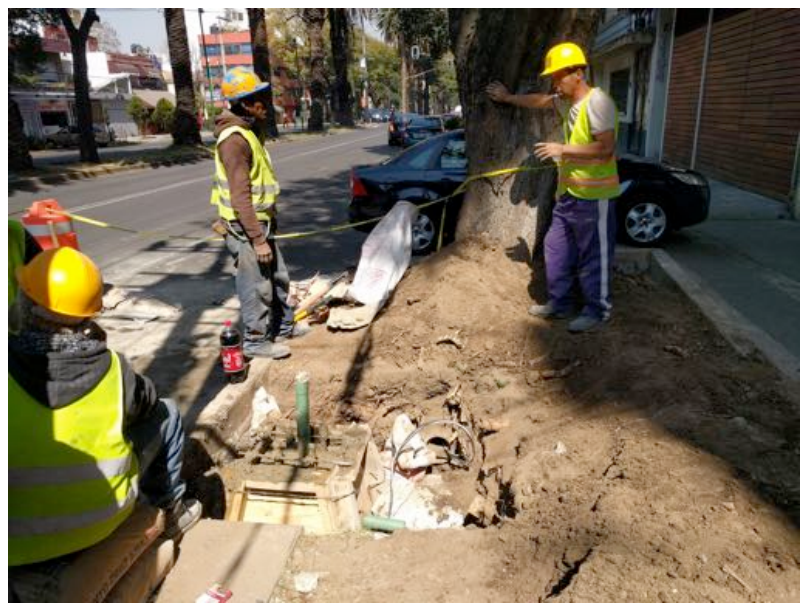

Figure 5. An example of maintenance work performed within the Critical Root Ratio (CRR) destroying part of the root, weakening the anchorage of a specimen and increasing the risk of tree failure. The species, a Jacaranda Mimosifolia, is a common species in Mexico City (CONABIO, 2012).

Modern cities require information of every aspect of the trees, both above and below ground. Tree inventories like i-Tree (USDA Forest Service, 2017) exist with above the ground emphasis but with no information regarding roots. The difficulty of modelling roots accurately can be the cause of the low number of urban trees inventories with emphasis on roots. Under this consideration, a simple geometric approach seems suitable to reduce the complexity of the task while enabling the spatial analysis between urban objects.

A geometric approach enables the analysis of tree roots interactions with urban infrastructure, including intersections between different objects and other spatial relationships. This paper presents a geometric aspect of tree roots with different amount of detail, key to enable the spatial analysis between urban objects, visualization and support the management of the underground space in urban environments.

\section{EXISTING MODELLING APPROACHES}

Several non-invasive and non-destructive techniques have been explored for scanning tree roots, including Ground Penetration Radar (Wielopolski et al, 2002) and X-Ray Computed Tomography (Heeraman et al, 1997). Both cases produce data slices and induce voxel representations. In most cases, volumetric rendering and iso-surfaces were obtained. In addition, a common assumption is to consider roots as cylindrical objects to compute volumetric information and visualization.

(Lopez et al., 2011) present a 3D scanning and recovering of 3D complex root structure based on 2D images, creating a skeleton graph and applying volumetric reconstruction based on cylindrical shapes, creating also a topologically connected root.
Despite the realistic results, the procedure is only applicable for scanning small vegetation growing on artificial transparent substrates, unlike the real environments where fully-grown trees exist.

Some authors consider that detailed roots can be geometrically modelled with using cylindrical shapes (Wilelopolski et al, 2002)(Lopez et al., 2011) but such approach requires knowledge about the actual structure of the root. Modelling detailed roots cannot be done without destructive methods or time-consuming Ground Penetration Radar scanning and given that roots keep growing, measurements should be updated frequently.

Achim et al. (2009) present a mechanistic resistance model of the anchorage strength for a shallow rooted tree, Sitka spruce or Picea sitchensis (Bong.) Carr., obtained from experimental data and based on easily measurable parameters: tree height, diameter at breast height (dbh), crown width, crown depth, live crown ratio, tree taper, measured of predicted root-soil plate spread and soil type. The root-soil plate is defined in geometric terms as a semi circular feature when viewed from above and simplified as a half circle. Under the assumption of a constant rooting depth along the plate, a vertical cylinder split in half with the corresponding rooting depth as the height parameter serves as the modelling geometry. In particular, deeper rooting is found to increase the anchorage strength depending on the root plate spread, with little variations between soil types.

\section{CONCEPTUAL PROPOSAL}

Research from Crow (2005), which studied roots from wind thrown trees, their root depth and spread into the soil, presents a root habit and three principal types of roots systems: taproot, heart root, and surface roots.

Taproot: a descending main strong root descends vertically from the underside of the trunk.

Heart Root: diagonal roots, large and small, descend diagonally from the trunk.

Surface Root: large, horizontal lateral roots extend below the soil surface. From these, small roots branch down vertically.

An artistic impression of the author is presented in Figure 6. for the considered roots. The classification is a modelling starting point where variability per species and exceptions can occur.
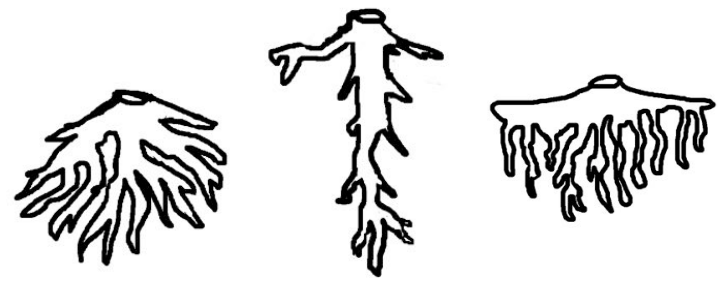

Figure 6. Author's artistic impression of the considered root systems. From left to right: Hearth root, Taproot, and surfaceroot systems.

Studies on the extent of the root plate are presented by (Stone, 1991) for maximal vertical and radial extents on various woody species. Data shows that trees develop deep and far-reaching roots in the absence of restrictive soil. In general, the soil mechanics, poorly aerated soils, and temperature limit the penetration of roots. The study from (Stone, 1991) reported root 
maximum radius extent ranging from $5 \mathrm{~m}$ up $30 \mathrm{~m}$ depending on species with some exceptions.

Typical relationship between canopy and root extension can be inferred and used for geometrical modelling where lateral roots extend up to the drip line (North Carolina Urban Forest Council, 2017). Some extensive works have been made towards describing species usually used for ornamental uses and compatible with overhead power lines and urban infrastructure (HYDRO-QUEBEC, 2010), (HYDRO-QUEBEC, 2017), including parameters like secure distance, height and width for a mature individual, growth rate, shape, type of branches, soil compatibility, rooting characteristics, usage, urban adaptability, among others. Such guides can provide classes of compatible vegetation with urban environments and information per species, useful as input values for parametric models, i.e. models where tree information is captured by a set of parameters.

The Critical Root Ratio (CRR) (Pokorny, 2003) defines the circular area of the root system around the trunk, critical for stability and vitality of the tree. The CRR usually extends beyond the dripline and damage higher than $40 \%$ within the CRR compromises the tree stability, however, this percentage varies between species. The CRR is defined as follows:

CRR (in feet ) $=1.5 \mathrm{x} \mathrm{dbh}$ (in inches) or equivalent in SI units, $\mathrm{CRR}($ in meters $)=18 \times \mathrm{dbh}(\text { in centimetres })^{*} 0.01$ )

For example, a $25.4 \mathrm{~cm}$ (10 inches) trunk diameter defines a CRR of $4.57 \mathrm{~m}$ (15 feet).

Regardless of the tree diameter, 6 feet $(1.82 \mathrm{~m})$ is considered as a minimum protection radius (North Carolina Urban Forest Council, 2017).

Similar root zones are presented by the Georgia Forestry Commission (2013), comprised of the Root Plate Radius, Critical Root Zone, and Total Zone Radius.

The Root Plate Radius (RPR) is defined as the "area of rapid tapering roots supporting the vertical weight of the tree." (Georgia Forestry Commission, 2013, p.4) and corresponds to half feet per measured inch of dbh.

$R P R$ (in feet) $=0.5 \times \mathrm{dbh}$ (in inches) or

$R P R($ in meters $)=6 \times \mathrm{dbh}$ (in centimetres $) * 0.01$

The Critical Root Zone (CRZ) ratio defines the minimum area, which should be left undisturbed in order to sustain a healthy tree and increase the chances of survival. The CRZ relationship corresponds to 1.3 feet of radius for every inch of dbh. For example, a $25.4 \mathrm{~cm}(10$ inches) trunk diameter defines a CRZ ratio of $3.96 \mathrm{~m}$ (13 feet). The relationship is expressed as follows:

CRZ(in feet $)=1.3 \times \mathrm{dbh}$ (in inches) or

$\mathrm{CRZ}($ in meters $)=15.6 * \mathrm{dbh}($ in centimetres $) * 0.01$

The Total Zone Radius (TZR) is considered the maximum extent of root area of a healthy tree and corresponds to 1.5 feet per measured inch of $\mathrm{dbh}$. The corresponding expression is:

$\mathrm{TZR}$ (in feet $)=1.5 \mathrm{x} \mathrm{dbh}$ (in inches) or

TZR (in meters $)=18^{*}(\mathrm{dbh}($ in centimetres $) * 0.01)$
In addition, Blackburn (2014) defines the Structural Root Plate (SRP) as one-third of feet per inch of dbh, expressed as follows:

$\operatorname{SRP}($ in feet $)=\operatorname{dbh}($ in inches $) / 3$ or

$\mathrm{SRP}($ in meters $)=4 \mathrm{x}(\mathrm{dbh}($ in centimetres $) * 0.01)$

In sum, when comparing the different radius and their proportions per measured inch, the following relationship is obtained followed by their corresponding proportions:

$\mathrm{SRP}<\mathrm{RPR}<\mathrm{CRZ}<\mathrm{TZR}=\mathrm{CRR}$

$0.33<0.5<1.3<1.5$

With respect to the depth of the roots, around $30 \%$ of all roots in tree species are present in the upper 4 inches of soil, and more than $50 \%$ in the top 12 inches (Abdi et al, 2010). Crow (2005) points out that between $90-95 \%$ of the total tree root occurs in the upper $1 \mathrm{~m}$ of soil and the $5 \%$ left do not occur in significant quantities at depths greater than $2 \mathrm{~m}$.

An experimental root-soil plate spread model from Achim et al. (2009), is useful for determining the geometric spread of shallow roots, integrates several above the ground parameters and serve as a crude representation of the below ground characteristics of the tree. In addition, the root-soil plate spread model is used to predict interactions with the built-in environment, compute the amount of damage taken by the root system by maintenance works and constructions and minimum distances to root-restricting features before anchorage strength is reduced.

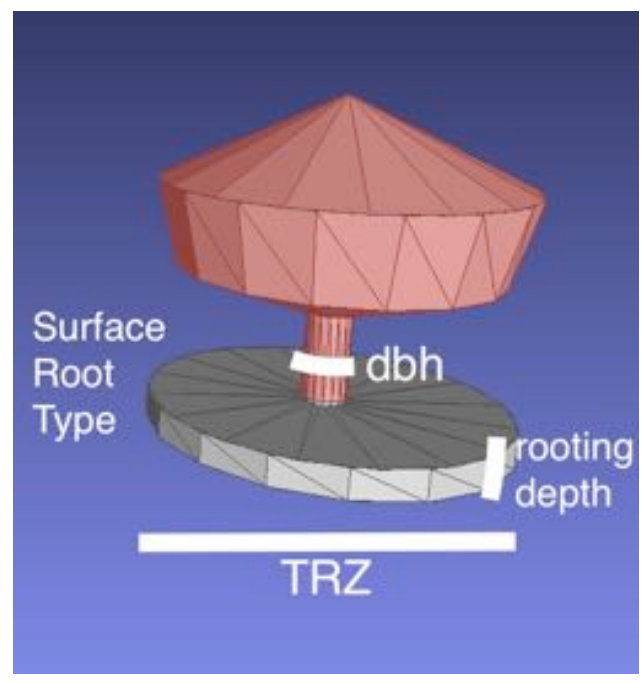

Figure 7. An example of a hypothetical tree species with a surface root type showing the parameters considered: Total Zone Radius or TZR, diameter at breast height and rooting depth.

So far, the stem size, DHB, or trunk diameter is a common parameter included into tree inventories like i-tree (USDA Forest Service, 2017) and used to define various tree root extents (Georgia Forestry Commission, 2013), being the TZR a comprehensive measurement of the root extent for a healthy tree and used here as a starting point for modelling tree root extents and analyzing tree interactions.

With this information, the ideal root of a healthy tree (not compromised) can be modelled as a function of its species, root type, trunk diameter or dbh, typical root depth and root extent or 
TZR. Figure 7 shows the considered parameters for a hypothetical tree.

Additional parameters including crown, soil, water availability and rooting restrictions may be included for modelling non ideal situations, however, further research may be needed to include them into a model. Other potential variables may include the age, overall health, and pruning frequency.

\section{GEOMETRIC PROPOSAL}

Detailed roots are complicated to model using only simple parameters and especially, to perform 3D spatial analysis with. However, urban elements and especially trees must be defined in $3 \mathrm{D}$ because interactions occur in 3D. The geometric proposal considers the root as the union of potentially occupied underground space under specific growth conditions. The union of space is simply the bounding geometry describing the potential growth of a tree root.

Cylinders and truncated cones are proposed as basic building blocks. A root may consist of a set of cylinders or truncated cones connected at their ends using different start and end ratios. This approach allows creating a set of topologically connected cylinders with watertight properties with simple parameters. A more generic approach could consider a 3D convex hull describing the root extension from scanned data, but also requires more computation time and precise information to compute it.

Simple geometric figures are representative of the root's occupied space, simple to build and simple to store as a set of build parameters.

The next section presents for each type of root considered, different bounding geometries at different levels of detail, producing an array of geometries suitable for different purposes.

\section{LEVELS OF DETAIL}

CityGML (Open Geospatial Consortium, 2012) is an information model for storage and representation of 3D city objects, including digital terrain models, buildings, bridges and tunnels, vegetation, water bodies, transportation facilities, city furniture and generic city objects. Each urban object can be represented in one of the 5 consecutive Levels of Detail (LOD), suitable for different scales and reflection of different data collection processes. LOD 0 scale is suitable for regional and landscape purposes, LOD 1 for the city and specific regions and LOD 2 for city districts or projects. LOD 3 and LOD 4 are oriented for architectural purposes.

CityGML 2.0 (Open Geospatial Consortium, 2012) distinguishes between solitary vegetation objects and vegetation areas. Vegetation areas use a simple geometric model described in terms of above the ground areas with no specifics regarding the LOD and how they match other element's LOD. The solitary vegetation object proposes the use of parametric objects, i.e. geometric objects created based on parameters, but does not mention the underground part of trees. In the case of the PlantCover feature, the specification considers vegetation covers as tools for realistic visualization but not for analysis. In general, the CityGML base specification is not intended to describe underground vegetation elements, but also underground modelling and descriptions are almost non-existent within its base specification.
The CityGML Application Domain Extensions (ADE) define an extension mechanism for incorporating additional information and models, and the inclusion of tree roots for Solitary Vegetation Objects can be accomplished with such approach. So far, a conceptual and geometrical model for tree roots have been described and the rest of the section will focus only on geometrical descriptions to match CityGML Levels of Detail.

Given the difficulty of measuring and capturing the actual root system architecture, sets of geometric versions are proposed with different complexities to model the roots' overall shape and extents. This approach defines a set of increasing complexity geometries comparable to CityGML LOD and the corresponding definitions are presented. The objects are defined using a Boundary Representation where the inside of the figure corresponds to the potentially occupied space by the root.

LOD 0: a surface model of the root lateral extension is projected onto the terrain surface, which can be further projected into the plane and made suitable for $2 \mathrm{D}$ analysis.

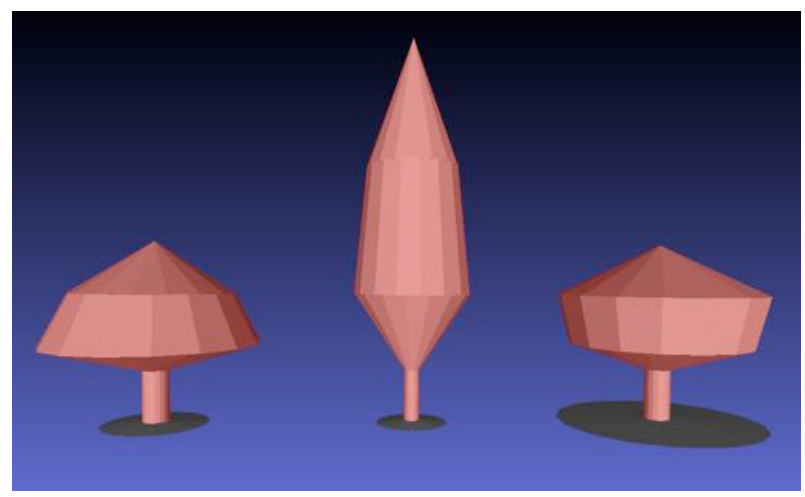

Figure 8. From Left to right, Heart-shaped root, Tap-root, and surface-root examples are presented as LOD 0 , where the horizontal influence area of the root is projected on the terrain. Hypothetical trees are presented in red above each root projection.

Parametrically, the Critical Root Ratio or Total Zone Radius can be used as a construction parameter for the defining the lateral extension for a healthy tree requiring only the trunk diameter or $\mathrm{dbh}$. However, CRR could extend beyond the drip line thus requiring the extension of the canopy. Actual cases may extend beyond the drip-line and require on site information. Urban environments pose space restrictions both above and below ground and definition of a minimum ratio can be helpful to establish the compatibility between trees, their roots, and the urban environment.

LOD 0 can be understood as a function of LOD 1 models or higher if derived from a $3 \mathrm{D}$ projection onto the terrain surface. Figure 8. presents an example of the LOD 0 root representation for the considered root types.

LOD 1: provides a basic 3D model considering the lateral root extension and rooting depth. Depending on the species, the root dimension changes and the shape must be modified accordingly. The depth of the root depends both on the type of root, the soil properties, age, and species. In terms of geometry, a simple cylinder is used to express the extension of the root for any given depth. Figure 9 depicts the root as a simple extrusion of the lateral extent down to the root depth. 
Information about depth and extension of roots is important to analyze possible interactions, establish conflicts with underground infrastructure and soil compatibility. Values for deep penetrating roots vary and can be obtained existing studies (Stone, 1991), however, they are valid for unrestricted growth conditions, and so further research is needed for urban environments.

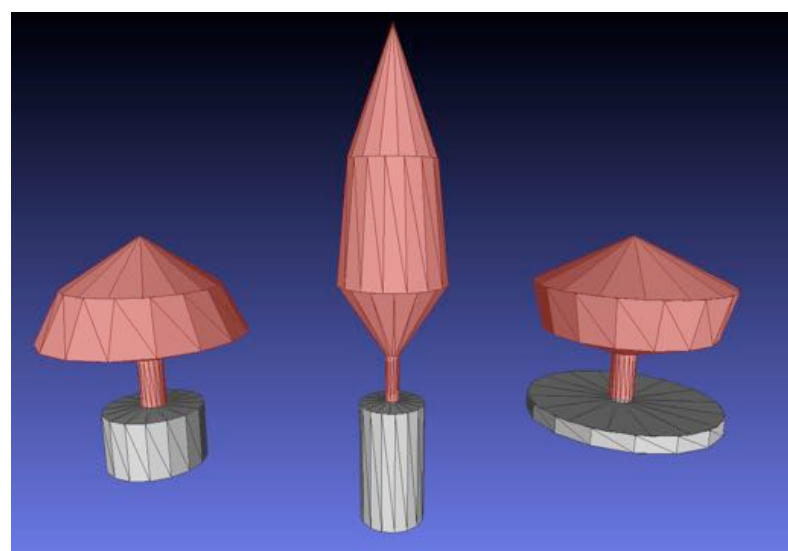

Figure 9: From Left to right, Heart-shaped root, Taproot and Surface-root examples are presented as LOD 1 in gray. A cylinder warping the horizontal influence area of the root is presented for each type of tree root. Hypothetical tree crowns and trunks in red are presented above each root as an example.

LOD 2: Tree roots have 3D geometries similar to its characteristic shape, introducing a visually appealing representation compared to LOD 1 simple cylinders but with the similar growth potential representation. Visually, having distinctive shapes serves as a guide towards differentiating roots and conflicts while keeping root parameters like depth and extension. Analytically, results should be comparable to LOD 1.

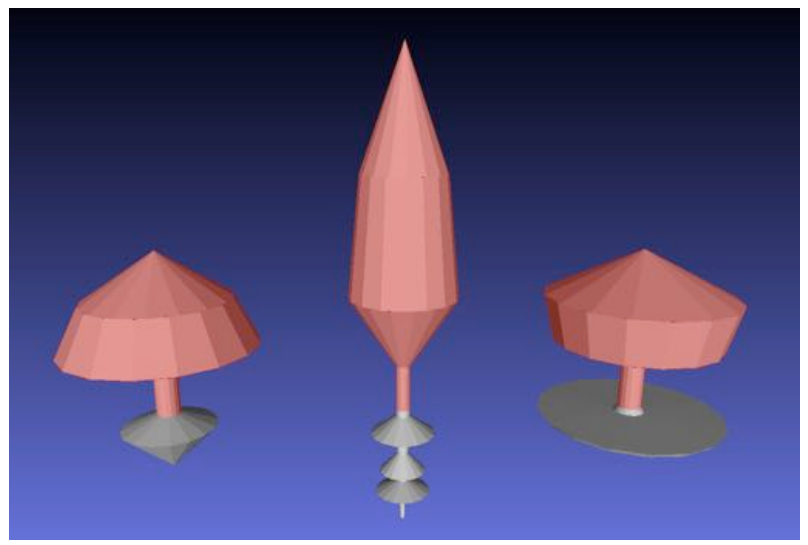

Figure 10: From left to right, Heart-shaped root, Taproot, and Surface-root examples are presented as LOD 2, expressing the type of root specific for each tree. A red tree in red is presented above each root as an example.

Roots are built from a set of truncated cones connected at their ends using different radios. The construction provides similar results to a $3 \mathrm{D}$ convex hull but with a simpler construction. Parametric construction of cones allows creating a topologically connected set of cylinders with watertight properties. Figure 10 shows examples of the proposed roots.

LOD 3 \& LOD 4: models can be derived from scanned data using Ground Penetration Radar or similar technologies. A 3D convex hull can be built around the data for LOD 3 and LOD 4 can be built using 3D alpha shapes ( $\mathrm{Da}, 2017)$. These levels are distinct from the previous levels because they represent actual space use rather than potential space and require data collection. No further examples are provided.

\section{CONCLUSIONS AND FUTURE WORK}

Modelling roots accurately is a challenging task given the invisible nature of the underground space. Non-invasive scanning methods like GPR or similar are required in order to preserve the species or otherwise employ destructive methods to scan the root and obtain exact parameters and models.

Definition of roots as potentially occupied space allows analyzing the underground space, tree roots and interactions with other urban objects without destroying the tree root system.

Relevant information exists to define root ratios and depths for some species and the proposed geometric models can be derived from reference parameters associated per species. Without specific information, the diameter at breast height can be used to define the Total Zone Radius or Critical Root Ratio, define an overall shape of roots, create visually appealing models and enable spatial analysis. The Critical Root Ratio serves also as an evaluation tool of the anchorage and survival chances of the tree.

Based on the geometric features, interactions between underground objects can be studied, as well as the damage induced to and from other urban objects or human activities. Additional analysis could take into account space and root volume, its area of influence, interactions with other objects and distance to nearby objects.

Reducing the universe of tree roots shapes down to three specific types allows covering many cases for trees and defines the LOD easily. The results can be used to extend existing urban models like CityGML where the Solitary Vegetation object model lacks a geometric definition for roots. Higher LOD are restricted to specimens where scanned data exist and can be used to create realistic models rather than potential occupied space models. Additional work is required towards integration of scanned data.

Further work should focus on creating tables for root dimensions of common species, especially on the lateral root extension and rooting depth, and continue working towards a CityGML ADE for Solitary Vegetation, where semantic and topologic information must be defined as well.

\section{REFERENCES}

Abdi, E., Majnounian, B., Rahimi, H. Zobeiri, M., Mashayekhi, Z. and Yosefzadeh, H., 2010. A comparison of root distribution of three hardwood species grown on a hillside in the Caspian forest, Iran, Journal of Forest Research 15:99-107.

Achim, A., Nicoll, B. C., 2009. Modelling the anchorage of shallow-rooted trees, Forestry: An International Journal of Forest Research, Volume 82, Issue 3, pp. 273-284. https://doi.org/10.1093/forestry/cpp004 
Blackburn, J., 2014. Trees, Critical Root Zones, and Construction: Building for Long Term Survivability, Arborguard Tree Specialists, GUFC College Canopy Conference. http://www.gufc.org/wp-content/uploads/2009/08/ Trees-Critical-Root-Zones-and-Construction.pdf (2 Jun. 2017)

Calaza, M., Iglesias, M., 2016. El riesgo del arbolado urbano. Contexto, concepto y evaluación, Ediciones Mundi-Prensa, $526 \mathrm{p}$.

Clementini, E., Felice, P.D., Oosterom, P. van, 1993. A Small Set of Formal Topological Relationships Suitable for End-User Interaction, in: Proceedings of the Third International Symposium on Advances in Spatial Databases, Proceedings of the Third International Symposium on Advances in Spatial Databases. Springer-Verlag, London, UK, UK, pp. 277-295.

Coder, K.D., 2014. Tree Anchorage \& Root Strength, University of Georgia, Warnell School of Forestry \& Natural Resources monograph publication, WSFNR14-9, pp.67

CONABIO, 2012. Guía de Campo: Árboles Comúnes de la Ciudad de México, Comision Nacional para el Conocimiento y Uso de la Biodiversidad, México.

Crow, P; 2005. The Influence of Soils and Species on Tree Root Depth, Information Note, Forestry Commission, FCIN078.

Da, T.K.F., Loriot, S., Yvinec, M., 2017. 3D Alpha Shapes, in: CGAL User and Reference Manual, CGAL User and Reference Manual. CGAL Editorial Board.

Georgia Forestry Commission, 2013. Recommended Community Tree Ordinance Tree Conservation Standards, Sustainable Community Forestry Program , http://www.gatrees.org/resources/publications/RecommendedC ommunityTreeOrdinanceTreeConservationStandards.pdf (2 Jul. 2017)

Gómez-Baggethun, E.; Barton, D. N., 2013. Classifying and valuing ecosystem services for urban planning, Ecological Economics, Vol. 86, pp. 235-245

Heeraman, D.A., Hopmans, J.W., Clausnitzer, V., 1997. Threedimensional imaging of plant roots in situ with X-ray Computed Tomography, Plant and Soil, 189: 167. https://doi.org/10.1023/B:PLSO.0000009694.64377.6f

HYDRO-QUEBEC, 2017, Util pour choisir le bon arbre ou arbuste, https://arbres.hydroquebec.com/recherche-arbresarbustes/ (1 Jun. 2017)

HYDRO-QUEBEC, 2010. Répertoire des arbres et arbustes ornementaux, Broquet.

Lopez, L. D., Shantharaj, D., Liu, L., Bais, H, Yu, J., 2011. Robust image-based 3D Modeling of Root Architecture, Proceedings of Computer Graphics International

Lyytimäki, J.; Sipilä, M., 2009. Hopping on one leg - The challenge of ecosystem disservices for urban green management, Urban Forestry \& Urban Greening 8, pp. 309-315

Mercer, G.; Reeves, A.; O'Callaghan, D., 2011. The relationship between trees, distance to buildings and subsidence events on shrinkable clay soil, Arboricultural Journal, Vol.33, pp. 229245, doi:10.1080/03071375.2011.9747615
North Carolina Urban Forest Council, 2017. Determining Critical Root Zone, http://www.ncufc.org/determining-rootzone.php, (10 May 2017)

Open Geospatial Consortium, 2012. OGC City Geography Markup Language (CityGML) Encoding Standard 2.0.0. Technical report, OGC 12-019

Overbeke, C., 2010. Does it really matter if there is a tree near a building?, http://www.localsurveyorsdirect.co.uk/sites/default/ files/attachments/treesdraft060227.pdf, (23 Jun. 2017)

Pokorny, J. D., 2003. Urban Tree Risk Management: A Community Guide to Program Design and Implementation, USDA Forest Service, Northeastern Area NA-TP-03-03

PostGIS, 2017. PostGIS 2.3.3 dev Manual, http://postgis.net/ docs/ST Relate.html (1 Jun. 2017)

Shamoon, T., 2012. Root Removal of Sweetgum Trees, http://homeguides.sfgate.com/root-removal-sweetgum-trees57872.html (1 Jun. 2017)

Stathers, R.J., T.P. Rollerson, and S.J. Mitchell., 1994. Windthrow handbook for British Columbia forests. B.C. Min. For., Victoria, B.C. Working Paper 9401.

Stone, E.L., Kalisz, P.J., 1991. On the maximum extent of tree roots, Forest Ecology Management, 46: 59-102.

University of California, 2010. California Tree Failure Report Program: A Ten-year look 2000/2010, http://ucanr.edu/sites/treefail/CTFRP_Statistics/A_Ten_Year_L ook_2000_2010/(10 Apr. 2017)

University of California, 2017. California Tree Failure Report Program Statistics, http://ucanr.edu/sites/treefail/ CTFRP_Statistics/ (10 Apr. 2017)

USDA Forest Service, 2017. i-Tree ECO User's Manual V6.0, https://www.itreetools.org/resources/manuals/Ecov6_ManualsG uides/Ecov6_UsersManual.pdf (1 Jun. 2017)

Wielopolski, L., Hendrey, G., McGuigan, M., Daniels, J.J., 2002. Imaging tree root systems In Situ, Proc. SPIE 4758, Ninth International Conference on Ground Penetrating Radar, pp. 5862. doi: $10.1117 / 12.462319$ 